\title{
Are gestational and type II diabetes mellitus associated with the Apgar scores of full-term neonates?
}

This article was published in the following Dove Press journal: International Journal of Women's Health

\author{
Kevin P Yeagle' \\ James Michael O'Brien² \\ William M Curtin² \\ Serdar H Ural ${ }^{2}$ \\ 'Penn State Hershey, Department of \\ the College of Medicine, Hershey, PA, \\ USA; ${ }^{2}$ Penn State Hershey Obstetrics \\ and Gynecology, Department of \\ Maternal Fetal Medicine, Hershey, \\ PA, USA
}

Objective: To compare Apgar scores of full-term newborns of mothers with gestational (GDM) or type II diabetes mellitus (T2DM) with scores of newborns of mothers without impaired glucose tolerance.

Study design: This was a retrospective data collection study $(\mathrm{n}=297)$. We reviewed 1-minute and 5-minute neonatal Apgar scores of newborns of mothers with GDM ( $n=100)$ or T2DM $(n=97)$. Our control group consisted of newborns of mothers without a prior history of impaired glucose tolerance $(n=100)$. ANOVA and linear model with corrected errors were used and adjusted for newborn sex and weight, and maternal age. Chi-squared analysis was performed for newborn sex.

Results: The mean 1-minute and 5-minute Apgar scores were 7.8 and 8.9 for the GDM group and 7.7 and 8.9 for the T2DM group, respectively. There was no statistical difference in the 1-minute and 5-minute Apgar scores between the GDM group and controls ( $P=0.89$ and $P=0.13$, respectively) nor in the scores between the T2DM group and controls ( $P=0.67$ and $P=0.40$, respectively).

Conclusion: Maternal history of GDM and T2DM does not appear to be associated with the 1-minute and 5-minute Apgar scores of full-term newborns of mothers with GDM and T2DM as compared to newborns of mothers without a history of impaired glucose tolerance.

Keywords: Apgar score, diabetes mellitus, gestational diabetes, term birth

\section{Introduction}

A method to assess the newborn's health status soon after birth was developed in 1952 by Apgar. ${ }^{1}$ The Apgar score is calculated based on the following five elements: heart rate, reflexes, color, muscle tone, and respiratory effort. Each component is scored from 0 to 2, with a total possible score of 10 at 1 minute and 5 minutes. Additional scores can be obtained at 5-minute intervals based on the status of the neonate. The Apgar score is utilized as a predictor of neonatal survival and to assess the need for resuscitative interventions. There are also limitations when using the Apgar score. The scoring system is influenced by multiple factors such as gestational age and infant maturity. Additionally, the specific elements are subjective to the scorer. Although it has some inherent limitations, its utilization for determining neonatal status after delivery is widely accepted..$^{2-4}$

Prior studies have demonstrated a correlation between low Apgar scores and prematurity and low birth weight. ${ }^{5,6}$ Lower Apgar scores were shown to be associated with an increased risk of mortality and perinatal complications in preterm infants. ${ }^{7}$
Correspondence: Kevin P Yeagle Penn State College of Medicine, 500 University Drive, 3rd Floor North, Hershey, PA 17033, USA

$\mathrm{Tel}+\mathrm{I} 71753 \mid 8142$

Email kyeagle@pennstatehealth.psu.edu 
Attempts have also been made to utilize Apgar scores for predicting a child's future health, but studies have yielded inconclusive results. ${ }^{8}$

Up to $5 \%$ of pregnancies are complicated by type I or II diabetes mellitus or gestational diabetes. Additionally, mothers with gestational diabetes have been shown to be at an increased risk of developing type II diabetes mellitus (T2DM) after pregnancy. ${ }^{9}$ Maternal diabetes mellitus is known to increase the risk of macrosomia in infants due to insulin resistance and greater exposure to glucose in utero, ${ }^{10,11}$ and increased fetal birth weigh has been linked to elevated second- and third-trimester postprandial glucose values. ${ }^{11}$ Macrosomic infants are at an increased risk of several complications including preterm birth, shoulder dystocia, and hypoglycemia. ${ }^{10}$ Shoulder dystocia in neonates of diabetic mothers is associated with lower Apgar scores at 1 minute though not at 5 minutes compared to neonates of nondiabetic mothers. ${ }^{12}$ A study comparing the Apgar scores of neonates of diabetic mothers and nondiabetic mothers would be useful in determining if maternal diabetes is in fact associated with lower 1-minute and 5-minute Apgar scores. The objective of this study is to compare the Apgar scores of full-term newborns of mothers with gestational diabetes mellitus (GDM) or T2DM with the scores of newborns of mothers without impaired glucose tolerance.

\section{Methods}

Through a retrospective chart review conducted at Penn State Health Milton S Hershey Medical Center in Hershey, PA, USA, we compared the Apgar scores ( $n=297,2007-2016)$ of newborns of mothers with a diagnosis of either GDM $(n=100)$ or T2DM ( $\mathrm{n}=97)$ and mothers without a history of diabetes mellitus $(n=100)$. This study was approved by Penn State College of Medicine IRB committee (STUDY00004581), and a waiver of exemption for patient consent was obtained as the study posed minimal harm to the subjects and did neither affect their care nor was any protected health information recorded. All newborns were born at full term (37 $0 / 7$ weeks or later). Inclusion criteria for the control group included neonates of full-term mothers (gestational age of 37 $0 / 7$ weeks or later) and no prior history of impaired glucose tolerance during or outside of pregnancy. Inclusion criteria for the GDM and T2DM groups included neonates of fullterm mothers (gestational age of 37 0/7 weeks or later) and either GDM during the current pregnancy or T2DM. GDM was defined as two elevated glucose values after $100 \mathrm{~g}$ oral glucose tolerance test (OGTT). This test was performed after a positive $50 \mathrm{~g}$ glucose screening test. T2DM was diagnosed by fasting plasma glucose $\geq 126 \mathrm{mg} / \mathrm{dL}, \mathrm{HbA} 1 \mathrm{C} \geq 6.5 \%$, random plasma glucose $\geq 200 \mathrm{mg} / \mathrm{dL}$ with symptoms of hyperglycemia, or plasma glucose $\geq 200 \mathrm{mg} / \mathrm{dL}$ after 2 -hour OGTT. Non-protected health information was collected and included maternal age, birth weight, gender, and 1-minute and 5-minute Apgar scores from 01/01/2011 to 06/22/2016. A total of 100 newborns of mothers without type II diabetes or gestational diabetes were included as the control group. To achieve a power of $80 \%$, a sample size of 97 per group was needed to detect a difference in Apgar scores of 0.5 between the two groups, assuming an SD of 1.2 derived from this study and having a significance level of 0.05 . Data of 97 newborns of mothers with T2DM and 100 newborns of mothers with GDM were collected. Statistical analysis was performed using SAS software, version 9.4 (SAS Institute Inc., Cary, NC, USA). Differences in mother's age and newborn's birth weight were tested using ANOVA. The sex of the newborn was assessed by using the chi-squared test. For statistical analysis of the 1-minute and 5-minute Apgar scores, a general linear model with correlated errors was used, due to repeated AGPAR assessments for each newborn, and was adjusted for newborn sex and weight, and maternal age.

\section{Results}

Newborns in the control group included 60 males (60\%) and 40 females (40\%) with an average weight of 3,383.3 $\mathrm{g}$ and a mean maternal age of 28.4 years (Table 1). In the GDM group, there were 52 males $(52 \%)$ and 48 females $(48 \%)$ with an average newborn weight of $3,561.5 \mathrm{~g}$ and a mean

Table I Mean maternal age and full-term newborn weight of control, GDM, and T2DM groups

\begin{tabular}{|c|c|c|c|c|c|c|}
\hline & $\begin{array}{l}\text { Control } \\
\text { mean (SD) }\end{array}$ & $\begin{array}{l}\text { GDM mean } \\
\text { (SD) }\end{array}$ & $\begin{array}{l}\text { T2DM } \\
\text { mean (SD) }\end{array}$ & $\begin{array}{l}\text { GDM vs control } \\
\text { difference in means } \\
(95 \% \mathrm{Cl})[P \text {-value }]\end{array}$ & $\begin{array}{l}\text { T2DM vs control } \\
\text { difference in means } \\
(95 \% \mathrm{Cl})[P \text {-value }]\end{array}$ & $\begin{array}{l}\text { T2DM vs GDM } \\
\text { difference in means } \\
(95 \% \mathrm{CI})[P \text {-value }]\end{array}$ \\
\hline $\begin{array}{l}\text { Maternal } \\
\text { age (years) }\end{array}$ & $28.4 \pm 5.3$ & $30.5 \pm 5.3$ & $31.2 \pm 5.5$ & $2.2(0.7-3.7)[<0.00 \mathrm{I}]$ & $2.8(I .3-4.3)[<0.00 I]$ & $0.7(-0.8-2.2)[0.38]$ \\
\hline Weight (g) & $3,383.3 \pm 592.3$ & $3,56 \mid .5 \pm 525.9$ & $3,635.2 \pm 602.3$ & I78.I (I8.3-338.0) [0.03] & $25 I .9(90.9-4 \mid 3.0)[<0.01]$ & $73.8(-87.3-234.8)[0.37]$ \\
\hline
\end{tabular}

Note: ANOVA was performed with corresponding $\mathrm{Cl}$ and $P$-values.

Abbreviations: GDM, gestational diabetes mellitus; T2DM, type II diabetes mellitus. 
Table 2 Comparison of sex between control, GDM, and T2DM groups

\begin{tabular}{lllllll}
\hline & $\begin{array}{l}\text { Control, } \% \\
\text { (number) }\end{array}$ & $\begin{array}{l}\text { GDM, } \% \\
\text { (number) }\end{array}$ & $\begin{array}{l}\text { T2DM, \% } \\
\text { (number) }\end{array}$ & $\begin{array}{l}\text { GDM vs } \\
\text { control, } P \text {-value }\end{array}$ & $\begin{array}{l}\text { T2DM vs } \\
\text { control, } P \text {-value }\end{array}$ & $\begin{array}{l}\text { T2DM vs } \\
\text { GDM, } P \text {-value }\end{array}$ \\
\hline Male & $60.0(60)$ & $52.0(52)$ & $59.8(58)$ & 0.25 & 0.98 & 0.27 \\
Female & $40.0(40)$ & $48.0(48)$ & $40.2(39)$ & & & \\
\hline
\end{tabular}

Note: Comparison was performed using a chi-squared test $\left(\chi^{2}\right)$ with corresponding $P$-values.

Abbreviations: GDM, gestational diabetes mellitus; T2DM, type II diabetes mellitus.

maternal age of 30.5 years. In the T2DM group, there were 58 males $(59.8 \%)$ and 39 females (40.2\%) with an average weight of 3,635.2 $\mathrm{g}$ and a mean maternal age of 31.2 years. The newborn sex was statistically significant neither between the control and the GDM or T2DM groups ( $P=0.25$ and $P=0.98$, respectively) nor between the GDM and T2DM groups ( $P=0.27)$ (Table 2$)$. The mean newborn weight and maternal age were both found to be higher in the GDM and T2DM groups. There were statistically significant differences in both age and weight between the GDM and the control group ( $P \leq 0.001$ and $P=0.03$, respectively) as well as between the T2DM and the control group ( $P \leq 0.001$ and $P \leq 0.01$, respectively). There was no statistically significant difference between the GDM and T2DM groups in either age or weight ( $P=0.38$ and $P=0.37$, respectively).

The mean 1-minute and 5-minute Apgar scores were 7.8 and 8.9 for the GDM group, and 7.7 and 8.9 for the T2DM group, respectively (Table 3 ). The mean 1-minute and 5-minute Apgar scores for the control group were 7.8 and 8.8 , respectively. There was neither difference in the mean 1-minute Apgar score between the GDM and control group $(P=0.89)$ nor was there a statistically significant difference in the mean 5-minute Apgar score $(P=0.13)$. There was also no statistically significant difference in the mean 1-minute and 5-minute Apgar scores between the T2DM and control groups ( $P=0.67$ and $P=0.40$, respectively).

\section{Discussion}

Our study showed that Apgar scores are not associated with maternal GDM or T2DM when compared to normal glucose tolerance in pregnancy. However, an association between maternal GDM and T2DM and newborn weight was found. There was a statistically significant difference in the maternal age as well as the newborn weight between the GDM and T2DM groups and the control group. The increased birth weight in newborns born to mothers with GDM or T2DM was not surprising considering that maternal GDM and T2DM exposes the fetus to increased levels of glucose during pregnancy. The increased exposure to glucose can lead to macrosomia in newborns. ${ }^{10,11}$ The older maternal age in the GDM group was expected as advanced maternal age is a risk factor for gestational diabetes. ${ }^{13}$ Advanced age is also a risk factor for the development of T2DM. ${ }^{14}$

The Apgar score is a useful tool in the assessment of short-term prognosis for survival, ${ }^{2}$ but it does have some limitations. The scores have not been validated for the prediction of long-term neurologic outcome, ${ }^{8}$ are only used as a measure at a single point in time, ${ }^{15}$ and can be influenced by several factors such as prematurity, maternal sedation, and inter-operator variability. ${ }^{5}$ However, low Apgar scores have been associated with neonatal mortality. ${ }^{2,16}$

There have been several studies on the neonatal outcomes associated with pregestational diabetes mellitus and GDM and Apgar scores. A study of 94 patients with GDM and 14 patients with T2DM showed lower 1-minute and 5-minute Apgar scores and increased incidence of perinatal morbidity of neonates compared to neonates of mothers without impaired glycemic control. ${ }^{17}$ Other studies have not shown a difference in the 5-minute Apgar scores between neonates of GDM mothers and nondiabetic mothers. ${ }^{18}$ Thus, there have been mixed results as to the association between

Table 3 The mean I-minute and 5 minute Apgar scores of control, GDM, and T2DM groups, adjusted for newborn sex, weight, and maternal age

\begin{tabular}{|c|c|c|c|c|c|c|}
\hline & $\begin{array}{l}\text { Control } \\
\text { mean } \\
\text { (SD) }\end{array}$ & $\begin{array}{l}\text { GDM } \\
\text { mean } \\
(\mathrm{SD})\end{array}$ & $\begin{array}{l}\text { T2DM } \\
\text { mean } \\
(\mathrm{SD})\end{array}$ & $\begin{array}{l}\text { GDM vs control } \\
\text { difference in means } \\
(95 \% \mathrm{Cl})[P \text {-value }]\end{array}$ & $\begin{array}{l}\text { T2DM vs control } \\
\text { difference in means } \\
(95 \% \mathrm{Cl})[P \text {-value }]\end{array}$ & $\begin{array}{l}\text { T2DM vs GDM } \\
\text { difference in means } \\
(95 \% \mathrm{Cl})[P \text {-value }]\end{array}$ \\
\hline I-Minute Apgar score & $7.8 \pm 0.9$ & $7.8 \pm 1.6$ & $7.7 \pm 1.5$ & $0.03(-0.36-0.4 I)[0.89]$ & $-0.08(-0.47-0.31)[0.67]$ & $-0.11(-0.50-0.27)[0.57]$ \\
\hline 5-Minute Apgar score & $8.8 \pm 0.7$ & $8.9 \pm 0.5$ & $8.9 \pm 0.5$ & $0.13(-0.04-0.29)[0.13]$ & $0.07(-0.10-0.24)[0.40]$ & $-0.06(-0.22-0.1 \mathrm{I})[0.50]$ \\
\hline
\end{tabular}

Note: ANOVA was performed with the corresponding $\mathrm{Cl}$ and $P$-values.

Abbreviations: GDM, gestational diabetes mellitus; T2DM, type II diabetes mellitus. 
the 1-minute and 5-minute Apgar scores and neonates of diabetic patients.

Our study showed that these conditions do not confer any statistically significant difference in 1-minute and 5-minute Apgar scores. There was no significant decrease in the 1-minute and 5-minute Apgar scores in infants of mothers with GDM or T2DM when compared to mothers without diabetes. While research has shown that there is an increased risk of very low birth weight in preterm infants of mothers with diabetes, ${ }^{5,6}$ there does not seem to be any apparent shortterm risks in the full-term infants of mothers with both GDM and T2DM. The Apgar scores of newborns of mothers with GDM or T2DM do not seem to be adversely affected.

Admittedly, there are a few potential confounders for this study, including obesity in the neonates of nondiabetic mothers as well as glycemic control in pregnancies complicated by GDM or T2DM, which could falsely show a lack of association between the groups. Obesity is known to increase the risk of adverse neonatal outcomes and macrosomia. ${ }^{10,19}$ Because glycemic control was not directly assessed in this study, it remains as a potential confounder. It is possible that the counseling provided to mothers during pregnancy could account for the lack of association observed in this study. Counseling on proper glycemic control is ideally provided prior to conception and throughout the pregnancy in women with T2DM as well as to those identified to be at risk for developing GDM. At our institution, this counseling is given by maternal fetal medicine providers.

Other possible confounding factors and limitations to this study include the lack of comparison of neonates of diabetic and nondiabetic mothers with respect to demographic factors such as race or ethnicity, or smoking status, which could have affected the overall results. Factors such as smoking status in the mother have also been known to adversely affect neonatal morbidity, ${ }^{20}$ and differences in neonatal morbidity have been observed when adjusted for different races or ethnicities. ${ }^{21}$ These factors may affect the observed results from this study.

Gestational diabetes constitutes $90 \%$ of all diabetes that is encountered in pregnancy. ${ }^{22}$ A hyperglycemic state has been demonstrated to be a toxic environment to a developing fetus and is often associated with adverse neonatal outcomes. ${ }^{23}$ In mothers with poor glycemic control, there is an increased risk of perineal tears, uterine atony leading to postpartum hemorrhage, as well as an emergency cesarean section. ${ }^{10}$ Neonates are at an increased risk of fetal macrosomia and associated complications including shoulder dystocia and need for operative vaginal delivery..$^{10,12}$ The Apgar score is a useful tool in the assessment of short-term prognosis, ${ }^{8}$ with lower scores being associated with neonatal mortality. ${ }^{2,16}$ One study, conducted in Scotland, UK, showed that low Apgar scores at 5 minutes was strongly associated with risk of neonatal and infant deaths. ${ }^{7}$ However, other committees assert that Apgar scores provide information on the status of the newborn and response to resuscitation if needed but do not predict individual neonatal mortality or neurologic outcome. ${ }^{15}$ Thus, the application of Apgar scores beyond short-term resuscitation is controversial. Our study looks at the potential association between the Apgar scores and maternal GDM or T2DM. This study does not attempt to predict long-term outcomes or neonatal mortality but instead focuses on the short-term assessment of newborns of mothers with impaired glucose tolerance.

There have been some studies which have analyzed the Apgar scores in diabetic populations. One such study reported that there was no association between mothers with GDM and low Apgar scores, but there was an increased risk of macrosomia. ${ }^{22}$ This study supports our conclusion that there is no association between Apgar scores and mothers with GDM. Our study expands on this prior study to include mothers with pregestational T2DM as well, given that this group is another population in which there are increased neonatal complications. ${ }^{10,12}$ Another study found that 1-minute and 5-minute Apgar scores were lower in newborns of mothers with T2DM. However, this study included fewer patients with T2DM ${ }^{17}$ compared to the present study. Our study was able to show that there was no association even when a greater number of mothers were included. A limitation of our study was not being able to include a group of newborns of mothers with type 1 diabetes mellitus to better examine the spectrum of diabetes and pregnancy.

\section{Conclusion}

The findings of our research indicate that 1-minute and 5-minute Apgar scores are not associated with maternal GDM or T2DM when compared to normal glucose tolerance in pregnancy. Additional studies are needed to further confirm the findings of this paper as well as expand the research to include mothers with type 1 diabetes mellitus and compare with mothers without diabetes.

\section{Disclosure}

The authors report no conflicts of interest in this work.

\section{References}

1. Apgar V, York N. A proposal for a new method of evaluation of the newborn infant. Curr Res Anesth Analg. 1953;32(4):260-267. 
2. Casey BM, Mcintire DD, Leveno KJ. The continuing value of the Apgar score for the assessment of newborn infants. $N$ Engl J Med. 2001; 344(7):467-471.

3. Jepson HA, Talashek ML, Tichy AM. The Apgar score: evolution, limitations, and scoring guidelines. Birth. 1991;18(2):83-92.

4. Hegyi T, Carbone T, Anwar M, et al. APGAR Score and its Components. Pediatrics. 1998;101:77-81.

5. Catlin EA, Carpenter MW, Brann BS 4th, et al. The Apgar score revisited: influence of gestational age. J Pediatr. 1986;109(5):865-868.

6. Weinberger B, Anwar M, Hegyi T, et al. Antecedents and neonatal consequences of low Apgar scores in preterm newborns: a population study. Arch Pediatr Adolesc Med. 2000;154(3):294.

7. Iliodromiti S, Mackay DF, Smith GC, Pell JP, Nelson SM. Apgar score and the risk of cause-specific infant mortality: a population-based cohort study. Lancet. 2014;384(9956):1749-1755.

8. Ehrenstein V. Association of Apgar scores with death and neurologic disability. Clin Epidemiol. 2009;1:45-53.

9. Bellamy L, Casas JP, Hingorani AD, Williams D. Type 2 diabetes mellitus after gestational diabetes: a systematic review and meta-analysis. Lancet. 2009;373(9677):1773-1779.

10. Kc K, Shakya S, Zhang H. Gestational diabetes mellitus and macrosomia: a literature review. Ann Nutr Metab. 2015;66 Suppl 2: 14-20.

11. Athukorala C, Crowther CA, Willson K; Austrailian Carbohydrate Intolerance Study in Pregnant Women (ACHOIS) Trial Group. Women with gestational diabetes mellitus in the ACHOIS trial: risk factors for shoulder dystocia. Aust N Z J Obstet Gynaecol. 2007;47(1):37-41.

12. Levy A, Sheiner E, Hammel RD, et al. Shoulder dystocia: a comparison of patients with and without diabetes mellitus. Arch Gynecol Obstet. 2006;273(4):203-206.

13. Khalil A, Syngelaki A, Maiz N, et al. Maternal age and adverse pregnancy outcome: A cohort study. Ultrasound Obstet Gynecol. 2013; 42(6):634-643.
14. Geiss LS, Wang J, Cheng YJ, et al. Prevalence and incidence trends for diagnosed diabetes among adults aged 20 to 79 years, United States, 1980-2012. JAMA. 2014;312(12):1218-1226.

15. The Apgar score. Committee Opinion No. 644. American College of Obstetricians and Gynecologists. Obstet Gynecol. 2015;126:e52-5.

16. Li F, Wu T, Lei X, et al. The apgar score and infant mortality. PLoS One. 2013;8(7):e69072-e69078.

17. Mitrović M, Stojić S, Tešić DS, et al. [The impact of diabetes mellitus on the course and outcome of pregnancy during a 5-year follow-up] Uticaj dijabetesa melitusa na tok i ishod trudnoće u 5-godišnjem praćenju. Vojnosanit Pregl. 2014;71(10): 907-914. Slovenian.

18. Grandi C, Tapia JL, Cardoso VC. Impact of maternal diabetes mellitus on mortality and morbidity of very low birth weight infants a multicenter Latin America study. J Pediatr. 2015;91(3):234-241.

19. Ehrenberg HM, Mercer BM, Catalano PM. The influence of obesity and diabetes on the prevalence of macrosomia. Am J Obstet Gynecol. 2004;191(3):964-968.

20. Mei-Dan E, Walfisch A, Weisz B, Elad M-D, Asnat W, Boaz W, et al. The unborn smoker: association between smoking during pregnancy and adverse perinatal outcomes. J Perinat Med. 2015; 43(5):553-558.

21. Nguyen BT, Cheng YW, Snowden JM, et al. The effect of race/ethnicity on adverse perinatal outcomes among patients with gestational diabetes mellitus. Am J Obstet Gynecol. 2012;207(4):322.e1-322.e6.

22. Ovesen PG, Jensen DM, Damm P, Rasmussen S, Kesmodel US Maternal and neonatal outcomes in pregnancies complicated by gestational diabetes. a nation-wide study. J Matern Fetal Neonatal Med. 2015;28(14):1720-1724.

23. Vambergue A, Fajardy I. Consequences of gestational and pregestational diabetes on placental function and birth weight. World J Diabetes. 2011;2(11):196-203.
International Journal of Women's Health

\section{Publish your work in this journal}

The International Journal of Women's Health is an international, peerreviewed open-access journal publishing original research, reports, editorials, reviews and commentaries on all aspects of women's healthcare including gynecology, obstetrics, and breast cancer. The manuscript management system is completely online and includes

\section{Dovepress}

a very quick and fair peer-review system, which is all easy to use. Visit http://www.dovepress.com/testimonials.php to read real quotes from published authors. 